\title{
Water Conservation in Urban Landscapes
}

\author{
Roger Kjelgren', Larry Rupp ${ }^{2}$, and Doug Kilgren ${ }^{3}$ \\ Department of Plants, Soils, and Biometeorology, Utah State University, Logan UT 84322
}

As in agriculture, amenity landscapes that have ornamental or utility value are irrigated when rain is insufficient to support expected growth. Irrigation to compensate for inadequate rainfall can be permanent in arid areas or temporary with short-term drought in highsummer-rainfall areas. Landscapes have additional irrigation requirements uncommon in agriculture. Most landscape plants need shortterm irrigation following planting until they establish new roots in the surrounding soil. Also, plants can be placed in landscape situations of very limited soil-water availability, such as aboveground planters, that require permanent irrigation regardless of the climate.

Unlike agriculture, performance of an amenity landscape is not measured with a quantifiable yield. Applying a known amount of a resource, such as water, to an agricultural crop results in a predictable yield response. Consequently, resource input can be economically optimized for yield output. By contrast, landscape performance is measured by how well it meets expectations of the user or the individual paying for installation and maintenance, who may or may not be one and the same. Expectations include aesthetic appearance, utility, such as shading and ground cover, and recreation. Since landscape performance is based on expectations rather than an objective measure, there is no marketplace to assign economic value to the landscape. Without a market value of performance, the value of a resource input cannot be measured.

The absence of a quantitative relationship between input of a resource such as water and the performance of a landscape makes water conservation both difficult and easy. Developing quantitative management practices is difficult when water conservation is a goal for such a wide range of end users and expectations. Clear management recommendations are further complicated by the diversity of species and their water use characteristics, which makes determining irrigation requirements very complex. Alternatively, water conservation is easier in amenity landscapes because the species diversity available to meet subjective, and highly variable, expectations allows a wide range of water conservation options. Water can be conserved either by traditional conservation approaches or just by changing species or expectations.

\section{LANDSCAPE WATER USE}

\section{Context of landscape water use}

Urban water use is generally not a large percentage of total water consumption when compared with agriculture within a state or region. Water demand for a metropolitan region, particularly in arid regions, can be substantial on localized scales (Postel, 1992). Demand from industry, personal use, and amenity landscapes can require water from a vast number of local watersheds. Since the majority of the populations of many western U.S. states are concentrated in rapidly growing urban areas, water is critical in supporting those populations and can potentially govern future growth.

The amount of water applied to landscapes as a component of total urban water use can be quantified in temperate regions where irrigation is seasonal (Fig. 1, top). Metered municipal water use closely follows increased summer evapotranspiration (ET) rates relative to rainfall. The volume of water applied to landscapes can be estimated by assuming that winter water use reflects only indoor consumption, since cold temperatures and absence of plant growth reduce the need for irrigation. This assumption is not entirely accurate, as there are

Received for publication 15 Sept. 1999. Accepted for publication 18 Oct. 1999. This research was supported by the Utah Agricultural Experiment Station, Utah State Univ., Logan, UT 84322-4810.

${ }^{1}$ Associate Professor; e-mail: rkj@ hort.usu.edu

${ }^{2}$ Professor.

${ }^{3}$ Graduate Student. other seasonal water uses, such as evaporative coolers and swimming pools, but evidence indicates that landscape irrigation accounts for most of the seasonal increase in municipal water use. When a severe water shortage in Seattle, Wash., in Summer 1992 resulted in the banning of turfgrass irrigation, consequent municipal water use did not deviate from winter levels (Fig. 1, bottom), indicating that increased seasonal water use in Seattle indeed goes to landscapes.

Water consumption for landscape use varies with rain and ET (Table 1). Applying the subtraction method described above to data from six cities around the United States, those in the summer-rainfall region east of the Mississippi River increase water use about one-third during the spring to fall growing season. Summing the increased seasonal water use showed that landscapes account for approximately $10 \%$ of total seasonal water consumption for these cities, the rest going to indoor and other, nonirrigation, uses. In the arid Mountain West, seasonal water use increases nearly 3 - to 4 -fold during the growing season, and landscapes can account from a third to nearly half of the total municipal yearly water use (Vickers, 1991).

The amount of water applied to landscapes can be divided into three levels of usage. The first level is water needed to meet baseline physiological plant water needs. The second level is water needed to compensate for system nonuniformity to ensure that the all plants receive the baseline level, particularly in turf. The third is water applied in excess of that needed by plants or for system uniformity, which is potentially conservable.

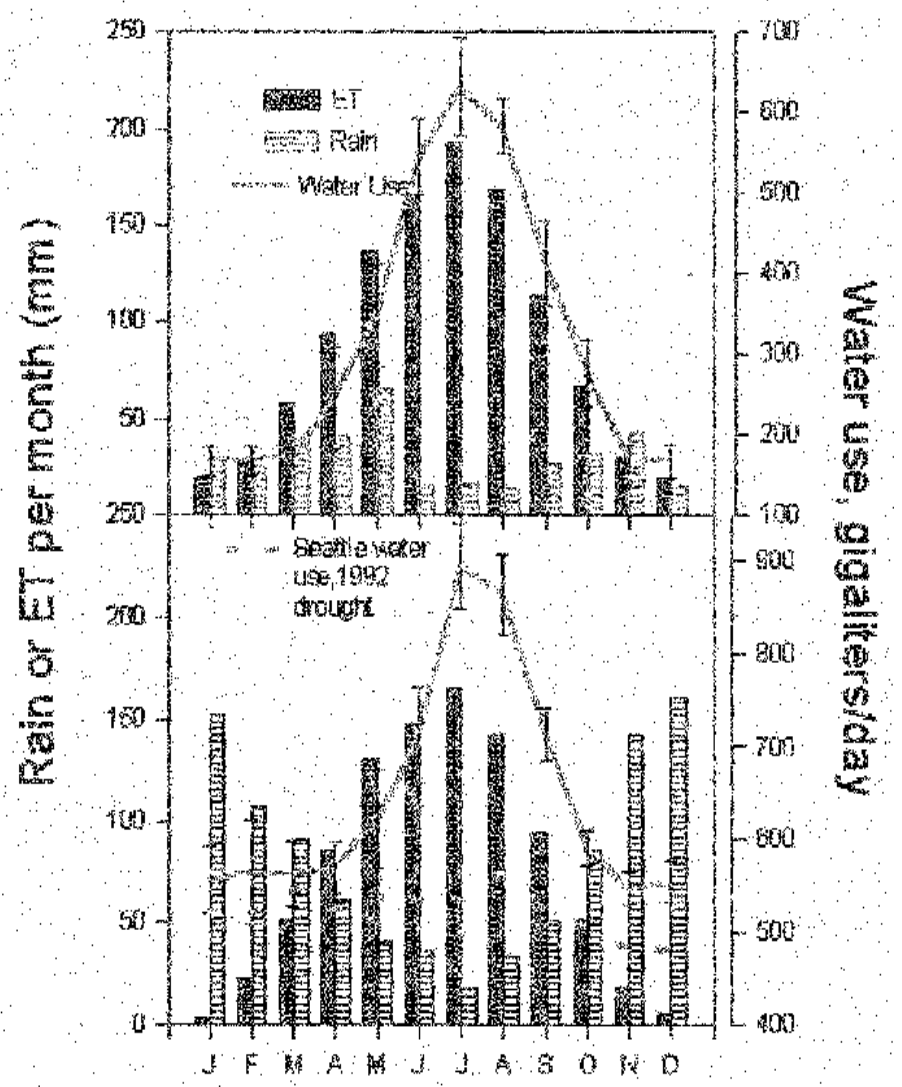

Fig. 1. Average monthly rainfall and reference evapotranspiration (ET; see Allen et al., 1994) and average daily municipal water use, plus standard deviation for (top) Salt Lake City, Utah, for the period 1990-94 (Source: Salt Lake City Water Conservancy District), and (bottom) for Seattle, Wash., for the period 1988-91, and water use during the drought year 1992 when lawn watering was banned. (Source: Seattle City Water Dept.). 
Table 1. Water balance, June, July, and August rainfall, reference evapotranspiration, and municipal water use for selected cities in the United States.

\begin{tabular}{lcccc}
\hline \hline & $\begin{array}{c}\text { Rain }^{z} \\
(\mathrm{~mm})\end{array}$ & $\begin{array}{c}\mathrm{ET}^{\mathrm{y}} \\
(\mathrm{mm})\end{array}$ & $\begin{array}{c}\text { Municipal water } \\
\text { use ratio } \\
\text { City }\end{array}$ & $\begin{array}{c}\text { Landscape }^{\mathrm{s}} \\
\text { water use }^{\mathrm{w}}\end{array}$ \\
\hline Detroit & 268 & 537 & 1.37 & 11 \\
Atlanta & 297 & 563 & 1.26 & 9 \\
Washington, D.C. & 302 & 549 & 1.35 & 13 \\
Seattle & 86 & 454 & 1.48 & 14 \\
Denver & 166 & 547 & 2.61 & 35 \\
Salt Lake City & 63 & 594 & 3.52 & 48 \\
\hline
\end{tabular}

${ }^{2}$ Data taken from soil surveys of the counties in which each city is located. ${ }^{y}$ For 0.12-m-high clipped fescue turf calculated as per Allen et al. (1994). xune, July, and August municipal water use divided by the winter baseline (December-February) water use.

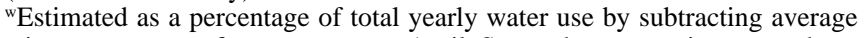
winter water use from water use April-September, summing over those months, then dividing by total yearly water use.

\section{Plant water needs}

Landscape plant cover. Landscapes are composed of plants such as turf, woody plants, herbaceous perennials, and annuals, and hardscape such as rocks, pavers, and mulch. Extent and type of plant cover varies enormously with the landscape. Parks and recreational areas are covered almost entirely with turfgrass, while for a typical residential lot half of the area is covered with a mixture of turf and woody plants (Limaye, 1996). Most of the plant cover in a landscape is turfgrass or trees imbedded in a turfgrass landscape, although the percentage of landscaped area composed of woody plants or herbaceous perennials may be larger in certain parts of the country.

Plant water loss. The physiological water needs of plants vary with atmospheric demand for water and plant characteristics. Atmospheric, or evaporative, demand for water is a function of radiation, humidity, air temperature, and wind. Plants regulate demand by varying leaf size and orientation, stomatal aperature, and total leaf area. Directly measuring plant water use for the practical purpose of replacing that water by irrigation is a difficult task. A more practical approach is relating actual plant water loss to a standard measure of atmospheric demand for water, such as an open pan of water, where:

actual plant water loss $\div$ pan evaporation $=\mathrm{Kc}$

where $\mathrm{Kc}$ is a proportionality factor, multiplier, or water loss coefficient. $\mathrm{Kc}$ is used to estimate water loss of a given plant or crop type if the standardized measure of atmospheric water demand is known. Pan evaporation often gave inconsistent results because of variation in local climatic and management conditions (Chiew and McMahon, 1991) and is now less widely used.

The advent of automated weather stations has allowed ready measurement of the atmospheric factors controlling evapotranspiration, and thus the development of a more robust standardized measure. The United Nations Food and Agricultural Organization has adopted the water loss rate of a hypothetical, uniform cool-season turf clipped at $0.12 \mathrm{~m}$ as the standard measure of reference evapotranspiration (ETo) using the Penman-Monteith equation (Allen et al., 1994). By holding plant-water-loss characteristics constant, a common measure of reference water loss can be compared among areas with different climates. The inputs needed to calculate ETo are wind, radiation, air temperature, and atmospheric humidity.

Water loss coefficients, Kc's, have been developed mostly for turfgrass because of turf's prevalence in most landscapes and its very close relationship to ETo. Values of Kc for cool-season turfgrass range from $85 \%$ to $100 \%$ of ETo while those for warm-season turf are $80 \%$ to $90 \%$ (65\% to $80 \%$ and $55 \%$ to $65 \%$, respectively, of evaporation pans) (Kneebone et al., 1992). Cultivar variability in Kc within a species is high, varying by $15 \%$ to $20 \%$ for several cool-season species (Shearman, 1989, 1991) and up to 60\% for Kentucky bluegrass (Poa pratensis L.) (Shearman, 1986).

There are few coefficients for nonturf landscape plants because of the great diversity of species and the difficulty in quantifying $\mathrm{Kc}$ values. For many woody species, rates of water loss are not a linear function of ETo. Stomatal sensitivity to high vapor pressure deficits (Turner et al., 1984) and close coupling to atmospheric conditions (Jarvis and McNaughton, 1986) result in a declining rate of water loss at high ETo rates (Choudhury and Monteith, 1986). Such nonlinearity suggests a wide range of Kc's, depending on ET conditions. Coefficients ranging from 0.2 to 0.8 of clipped fescue ETo have been suggested for woody plants (Costello et al., 1992). Limited experimental evidence indicates that water loss rates for temperate-climate woody species do indeed vary widely with both plant and environmental factors (Buwalda and Lenz, 1993; Kjelgren and Montague, 1996; Lindsay and Bassuk, 1991), but in general are lower than for turfgrass.

\section{Irrigation system nonuniformity}

The amount of water applied to amenity landscapes is nearly always increased over baseline plant water needs to account for nonuniformity in application. Again, the widespread use of turfgrass in such landscapes dictates performance that is measured by color and uniformity. To achieve a uniform appearance, the depth of water applied to turfgrass needs to be the same throughout the area in turf. Sprinkler irrigation is the most effective means of applying water uniformly. Uneven sprinkler application due to poor design or maintenance results in some areas receiving less water than others. Such areas have limited opportunity to exploit further water supplies during soil drying. Turf roots are circumscribed by competition with other plants laterally and are genetically limited in rooting depth. Consequently, nonuniform water application to turf is clearly evident in areas receiving less water, becoming, in general, unacceptably discolored from drought-induced dormancy.

Distribution uniformity (DU) for sprinkler irrigation is determined by a catch-can test. The depth of water in a number of cups spread evenly over the turf area is measured after the system has been operated for a fixed period of time. Such measurements are more feasible when a small sample area is used rather than the entire landscape. Fractional uniformity, between $0-1$, is calculated as the average depth of water in the $25 \%$ of the cups receiving the least amount of water divided by the average for all the cups. A sprinkler system that applies the same depth of water over the entire coverage area would have a DU of $100 \%$. By contrast, a DU of $50 \%$ means that part of the turf receives half the average amount (Goldhamer and Snyder, 1989). A lawn irrigated with a system with a DU of $50 \%$ would need twice the amount of water to ensure that the dry areas received enough than if the system had a DU of $100 \%$.

The DU of a sprinkler system varies with the type of sprinkler head. With optimum design, DU values of impact/gear drive sprinklers for large turf areas can be up to $90 \%$, while those of spray heads in small turf areas rarely exceed $75 \%$. In reality, DU values will vary widely within a head type because of numerous factors. We measured sprinkler DU of both impact and spray heads for 30 elementary schools in the metropolitan region of Salt Lake City, Utah (Table 2). Twenty of the schools had irrigation systems where sprinkler heads were moved manually around the landscape. Ten of the schools had automated irrigation systems where operation of all heads was controlled by a time clock attached to solenoid valves. Schools with automated systems had somewhat higher uniformity for both head types because they were installed more recently than were those at schools with older, manual systems. The range of uniformities for spray heads was greater than for impact sprinklers because of erratic replacement of broken spray heads with different makes that may have had higher or lower output than the original heads. Few schools had a DU above $80 \%$ for either head type.

\section{Conservable water}

Water applied in excess of plant water needs and expected system uniformity can be conserved. For a given landscape, the amount of conservable water can be calculated with an auditing approach. The volume of water applied to the landscape can be determined as described for Fig. 1 from water meter data for temperate regions without year-round irrigation. Dividing the volume of water estimated to be used on the landscape by the irrigated area gives the depth of applied water. This depth of water can then be compared with needs derived from the base plant water needs plus the amount needed to correct for system nonuniformity. 
Table 2. Percentage of elementary schools, 20 with manual irrrigation systems and 10 with automated irrigation systems, in Salt Lake City, Utah, having distribution uniformity of sprinkler systems for two head types (pop-up spray and impact) within a given range.

\begin{tabular}{lccccc}
\hline \hline $\begin{array}{l}\text { Distribution } \\
\text { uniformity }\end{array}$ & \multicolumn{2}{c}{ Spray head } & & \multicolumn{2}{c}{ Impact Head } \\
\cline { 2 - 3 } \cline { 5 - 6 } range $^{\mathrm{z}}$ & Manual & Automated & & Manual & Automated \\
\hline $0.21-0.3$ & 4 & 0 & & 0 & 0 \\
$0.31-0.4$ & 8 & 0 & & 20 & 0 \\
$0.41-0.5$ & 4 & 10 & & 30 & 30 \\
$0.51-0.6$ & 28 & 40 & & 30 & 30 \\
$0.61-0.7$ & 24 & 30 & & 15 & 0 \\
$0.71-0.8$ & 16 & 20 & & 0 & 0 \\
$0.81-0.9$ & 8 & 0 & 0 & 0 \\
$0.91-1.0$ & 8 & 0 & & 0
\end{tabular}

${ }^{2}$ Distribution uniformity is calculated from the collection of water in 36 cups or cans in a grid pattern.

Excess watering is due to nonuniform and inefficient application. Application uniformity less than the expected range for a given head type results in excess water applied to meet the needs of the dry areas. Low DU due to improper maintenance, such as obstructed or improperly nozzled heads, or operation during windy periods, can be improved through maintenance and different operation times. Low uniformity from improper design of head spacing and pressure control is more difficult to correct. Application efficiency is a measure of how much of the applied water is in the root zone after an irrigation. Inefficiencies occur when water is applied to pavement, runs off slopes, or percolates below the root zone due to improper design, maintenance, or operation. Inefficient application is closely related to, and often affects, DU. The end result is application of more water than is needed by plants in order to compensate for water not reaching the root zone.

Excess irrigation occurs when water is cheap and easy to apply. In the absence of market incentives, such as expensive water, water is used without consideration of cost. Federal subsidies in the West have resulted in water available to agriculture below the cost of development, a benefit often enjoyed by many municipal water districts (McCool, 1995). In addition, irrigation systems with automated time clocks make excess irrigation quite convenient. Time clocks are often set for peak evaporative demand and are rarely changed to reflect changing plant water needs early or late in the season. Again, in our study of 30 elementary schools in the Salt Lake City metropolitan region, we compared depth of water applied at schools with manual versus automated irrigation systems to estimate historical water needs (Table 3 ). While there was much variation among schools, over 5 years the elementary schools with automated systems consistently applied more water than did schools with manual systems. The effort involved in manual irrigation systems is a disincentive to waste water. Similarly, the Contra Costa Water District (CCWD) near Oakland, Calif., performed this analysis on 62 customers, and showed that the average over irrigation was in excess of $800 \mathrm{~mm} /$ year (personal communication with CCWD). Irrigation duration that was increased in response to higher ETo during spring and early summer was not revised downward as ETo fell in late summer-autumn, resulting in the greatest excess irrigation in September.

\section{LANDSCAPE WATER CONSERVATION}

\section{Water conservation situations}

Short-term conservation. Landscape water conservation becomes critical during drought periods when there is insufficient water to supply normal landscape irrigation. Often municipalities will ask water consumers to reduce use on a temporary basis. Short-term conservation measures such as alternate-day watering or bans on turf irrigation are intended for quick results, but do not reflect plant water needs and are not always effective. The tacit understanding with shortterm conservation is that normal consumption can resume once the emergency has passed.

Long-term conservation. Long-term conservation occurs when supplies no longer support existing or anticipated future demand, or when the cost of delivering water becomes sufficiently high to alter
Table 3. Average amount of water applied in excess of estimated water needs, based on evapotranspiration rate, at elementary schools in Salt Lake County, Utah.

\begin{tabular}{lccccc}
\hline & \multicolumn{2}{c}{ Manual } & & \multicolumn{2}{c}{ Automated } \\
\cline { 2 - 3 } \cline { 5 - 6 } Year & $\begin{array}{c}\text { Schools } \\
\text { (no.) }\end{array}$ & $\begin{array}{c}\text { Excess } \\
\text { irrigation } \\
(\mathrm{mm})\end{array}$ & & $\begin{array}{c}\text { Schools } \\
(\text { no. })\end{array}$ & $\begin{array}{c}\text { Excess } \\
\text { irrigation, } \\
(\mathrm{mm})\end{array}$ \\
\hline 1991 & 17 & $57 \pm 72^{\mathrm{z}}$ & & 9 & $104 \pm 102$ \\
1992 & 17 & $52 \pm 54$ & & 9 & $180 \pm 83$ \\
1993 & 18 & $67 \pm 66$ & & 8 & $176 \pm 67$ \\
1994 & 20 & $40 \pm 85$ & & 8 & $175 \pm 103$ \\
1995 & 20 & $20 \pm 66$ & 8 & $88 \pm 84$ \\
\hline
\end{tabular}

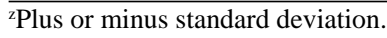

demand. Water purveyors responding to diminished future supplies may choose to intentionally reduce demand to prolong existing supplies. Purveyors choosing not to reduce current demand inevitably cause future reductions in demand by having to pass on costs of developing expensive new water sources. Public sentiment, however, is turning against development of new water projects to meet urban demand that would compete with alternative water uses, such as maintaining in-stream flow for fishing and recreation.

\section{Methods of water conservation}

Precision landscape irrigation. Uniform turfgrass, particularly cool-season turf, landscapes can be considered as the benchmark for high water use because of their need for uniform appearance compared with the nonuniformity and generally lower water needs of woody and other, nonturfgrass, perennial plants. Precision landscape irrigation can conserve water in any existing landscape, particularly sprinklerirrigated turfgrass, by reducing the amount applied inefficiently in excess of plant and nonuniformity needs. Improving irrigation system uniformity and efficiency by correcting design, operations, and maintenance problems is the first step in precision irrigation. Irrigations can then be precisely scheduled by setting the system to run long enough to replace soil water estimated to be lost to ETo and to compensate for system nonuniformity. Scheduling irrigations daily to replace the previous day's water loss to ETo is simple to program with a time clock, but can potentially increase evaporation loss and encourages shallow rooting. Alternatively, if soil water-holding capacity and rooting depth are known, or if tensiometers are used, the soil can be allowed to dry down to the point of incipient water stress, and water applied at that point to uniformly refill the soil profile (Goldhamer and Snyder, 1989).

Alternative water sources. Most landscapes are irrigated with treated, potable water that is expensive compared with untreated water. Golf courses with high water needs have reduced demand for potable water by using lake or stream water. While reducing the pressure on water agencies for development of new sources of potable water, using untreated lake/stream water does not conserve water on a watershed basis. An under-utilized water source for landscapes is water reclaimed from sewage effluent after secondary or tertiary treatment. While more expensive than conservation, irrigating with reclaimed water is much cheaper than developing new water sources for landscape irrigation (Postel, 1992). This practice is becoming widespread in California and Florida (Parnell, 1988) where effluent water is delivered to landscapes with specially designated (violetcolored pipe) delivery systems. Reclaimed water, however, is generally higher in soluble salts than is potable water, and must be applied at high enough rates to ensure a leaching fraction that avoids salt buildup in the soil (Hayes et al., 1990). Finally, in a number of states that consume significant amounts of water for landscape irrigation, use of effluent water on the landscape is still illegal. Another aspect of irrigating landscapes with reclaimed water is onsite use of gray (sink and shower) water and cisterns for rainfall capture.

Low-water use landscapes. Precision landscape irrigation can reduce excess irrigation to meet baseline plant and system uniformity needs. To conserve water below this baseline requires replacing turfgrass with nonuniform plant material that look acceptable at incipient water stress, and changing landscape expectations. How much water can be potentially conserved below the turf baseline will depend on the extent of nonuniformity of the plant cover (species 


\section{Colloquium}

diversity) and degree of drought adaptation of the plant material. Even a uniform, sprinkler-irrigated landscape of herbaceous perennials or woody plants can potentially use less water than a turf landscape. Trees, shrubs, and perennials generally avoid drought more effectively, and respond to drought more acceptably, than turfgrass. Many woody and herbaceous perennial species root more deeply, exploiting more soil and thus requiring less frequent irrigation with less irrigation water lost to evaporation. Many nonturf landscape species also maintain an acceptable appearance, maintaining turgid, green foliage at incipient water stress, unlike most turfgrass species that go dormant and turn an undesirable color.

The use of nonuniform landscapes consisting of herbaceous perennials, shrubs and trees can potentially use less water, apart from frequent irrigation needed during establishment, than turfgrass-dominated landscapes. In particular, nonuniform landscapes can use lowvolume irrigation (drip or micro-spray) that greatly reduces water use by targeting application to the plant root zone, and also reduces water loss from evaporation and runoff, and the need for uniformity. Dripirrigated woody plants that typically have partially wetted root zones can achieve sufficient water uptake through hydraulic lift and transfer to drier areas of the root zone (Dawson, 1993; Green and Clothier, 1995).

Nonirrigated amenity landscapes will obviously conserve the most water. Nonirrigated landscapes require plants that are adapted to local rainfall conditions, such that they exist on stored soil water and have acceptable appearance even when drought-stressed. Successfully using such plants requires soil conditions that allow exploitation of as large a root zone and as much soil moisture as possible. In arid regions, species adapted to drought are typically deep-rooted. If such plants are used in shallow, compacted, or highly confined soils or beds, their ability to withstand drought is severely compromised. In summer rainfall regions with native forest vegetation, one can readily achieve a nonirrigated landscape by simply allowing natural forest regeneration.

\section{Implementing water conservation}

Successfully conserving water on a short- or long-term basis in amenity landscapes means changing the behavior of large numbers of people while maintaining landscapes that meet their expectations. Voluntary or mandated water conservation during moderate shortterm drought is an infrequent occurrence that invokes a sacrifice mentality, which is, again, tolerable if traditional landscape practices can resume once the emergency has passed. Requests for voluntary conservation, however, sometime result in increased water use (Anonymous, 1998, Logan City, Utah, Engineering Dept., and Layton City, Utah, Engineering Dept.). Successful conservation in response to severe short-term drought or long-term water shortage requires changing expectations together with maintaining a landscape that meets those expectations. Precision irrigation or low-water-use landscaping are the most suitable long-term conservation methods, but must be implemented with educational and incentive measures, and policy changes, in order to succeed.

Several western communities have experimented with ways to conserve water during drought and to reduce long-term demand. Seattle banned lawn irrigation during its 1992 drought (Fig. 1, bottom), but consumers stopped irrigating all landscape plants. The water department then raised rates to recover lost revenue and subsequently, and not surprisingly, was not held in high esteem by consumers. Tucson, Ariz., has combined regulations restricting turfgrass areas and nonapproved, high-water-use woody plants with an educational program for new landscapes.

California implemented a state-wide model ordinance, state act AB 325 , to conserve landscape water using a water-budget approach. The product of ETo, a Kc for the chosen plant material, and an irrigation effectiveness factor (equivalent to the inverse of DU) must be less than a ceiling allocation of $80 \%$ of ET. While this approach uses a landscape water budget that better reflects the physiological water needs of the landscape plants, it has not been widely adopted because of lack of enforcement mechanisms and the difficulty of setting Kc values for nonturf plants. The Contra Costa Water District combined this ordinance with an educational program, and subsequently conducted water audits for a number of customers comparing on-going use to estimated needs. Water savings declined from $20 \%$ to $7 \%$ over a 3 -year period after the educational training, suggesting that education alone cannot sustain a permanent change in landscape watering behavior.

The Irvine Ranch Water District (IRWD), Calif., adopted a water budget approach that combined regulation, education, and incentives. They calculated a baseline landscape water-budget allocation based on landscaped area, system efficiency factor, and a Kc of $80 \%$, but substituted a tiered pricing structure in place of the ceiling allocation. The landscape water allocation calculated from this equation was assigned as the base price rate. Water price doubled for every $10 \%$ increase in water consumption above the base allocation, to a maximum of eight times the base allocation rate. This pricing structure was combined with a comprehensive educational program, and IRWD has reported a $45 \%$ decline in water use over the 6 years since implementation (personal communication with IRWD). The IRWD approach is gaining substantial interest in California, and will likely be examined very closely by the rest of the arid West.

\section{SUMMARY}

As limited fresh-water supplies, particularly in arid regions, meet increased urban demand for water, landscape water conservation will become more important. A variety of methods to conserve water and/ or moderate demand are available to water managers and consumers. Precision landscape irrigation can moderate demand to levels needed to meet plant and system uniformity needs. Precision-irrigated turf landscapes still consume large amounts of water. The value of extensive turfgrass in golf courses, formal gardens, and recreational fields can often offset the cost of water. In many landscapes turf is used out of habit or ease and cost of installation, with little thought given to alternative designs using plant material that is less resource-intensive. As water costs and demand rise, the cost of conventional landscapes with turfgrass used mindlessly also increases, thus mindful alternatives such as low-water-use landscapes will become more common.

\section{Literature Cited}

Allen, R.G., M. Smith, L.S. Pereira, and A. Perrier. 1994. An update for the definition of reference evapotranspiration. Intl. Comm. Irr. Drainage Bul. 43:1-92.

Buwalda, J.G. and F. Lenz. 1993. Water use by European pear trees growing in drainage lysimeters. J. Hort. Sci. 70:531-540.

Choudhury, B. and J. Monteith. 1986. Implications of stomatal response to saturation deficit for the heat balance of vegetation. Agr. Meteorol. 36:215-225.

Costello, L., N. Matheny, and J. Clark. 1992. Estimating crop coefficients for landscape plantings. Univ. California. Agr. and Nat. Res. Leaflet 21493, Berkeley.

Chiew, F. and T. McMahon. 1991. An Australian comparison of Penman's potential evapotranspiration estimated and Class-A evaporation pan data. Aust. J. Soil Res. 30:101-112.

Dawson, T.E . 1993. Hydraulic lift and water use by plants-Implications for water balance, performance and plant-plant interactions. Oecologia 95:565-574.

Goldhamer, D. and R. Snyder. 1989. Irrigation scheduling: A guide to efficient on-farm water management. Univ. of California Pub. 21454, Berkeley.

Green, S.R. and B.E Clothier. 1995. Root water uptake by kiwifruit vines following partial wetting of the root zone. Plant Soil. 173:317-328.

Hayes, A., C. Mancino, and I. Pepper. 1990. Irrigation of turfgrass with secondary sewage effluent: I. Soil and leachate water quality. Agron. J. 82:939-943.

Jarvis, P. and K. McNaughton. 1986. Stomatal control of transpiration: Scaling up from leaf to region. Adv. Ecol. Res. 15:1-49.

Kjelgren, R. and T. Montague. 1996. Isolated tree water use in various urban surfaces. ASAE Intl. Conf. on Evapotranspiration and Irr. Scheduling. San Antonio, Tex., $3-$ 6 Nov. 1996.

Kneebone, W., D. Kopec, and C. Mancino. 1992. Water requirements and irrigation, p. 441-472. In: D. Waddinton, R. Carrow, and R. Shearman (eds). Turfgrass. Amer. Soc. Agron. Ser. No. 32.

Limaye, U. 1996. Analysis of residential water demand using multispectral videography and other electronic databases. PhD Diss., Dept. Biol. and Irr. Eng., Utah State Univ., Logan.

Lindsey P. and N. Bassuk. 1991. Specifying soil volumes to meet the water needs of mature urban street trees and trees in containers. J. Arboricult. 17:141-149.

McCool, D. 1995. Waters of Zion: The politics of water in Utah. Univ. Utah Press, Salt Lake City.

Parnell, J. 1988. Irrigation of landscape ornamentals using reclaimed water. Proc. Fla. Sate Hort. Soc. 101:107-110.

Postel, S. 1992. Last oasis: Facing water scarcity. W.W. Norton Co., New York.

Shearman, R.C. 1986. Kentucky bluegrass cultivar evapotranspiration rates. HortScience 21:455-457.

Shearman, R.C. 1989. Perennial ryegrass cultivar evapotranspiration rates. HortScience 24:767-769.

Shearman, R.C. 1991. Creeping bentgrass cultivar water use and rooting responses. Crop Sci. 31:1331-1334

Turner, N., E. Schulze, and T. Gollan. 1984. The responses of stomata and leaf gas exchange to vapour pressure deficits and soil water content. Oecologia 63:338-342.

Vickers, A. 1991. The emerging demand-side era in water management. J. Amer. Water Works Assn. 83:38-43. 